\title{
Mobile Love in China: The Cultural Meaning and Social Implications of Mobile Communications in Romantic Relationships among Young Chinese Adults
}

\author{
Katrin Büchenbacher, Chen-Wei Chang* \\ School of Journalism, Fudan University, Shanghai, China \\ Email: *cwchang@fudan.edu.cn
}

How to cite this paper: Büchenbacher, K., \& Chang, C.-W. (2018). Mobile Love in China: The Cultural Meaning and Social Implications of Mobile Communications in Romantic Relationships among Young Chinese Adults. Advances in Journalism and Communication, 6, 38-54.

https://doi.org/10.4236/ajc.2018.62004

Received: March 21, 2018

Accepted: May 8, 2018

Published: May 11, 2018

Copyright $\odot 2018$ by authors and Scientific Research Publishing Inc. This work is licensed under the Creative Commons Attribution International License (CC BY 4.0).

http://creativecommons.org/licenses/by/4.0/

\begin{abstract}
The current study takes a qualitative approach to examining the unique use of mobile communications in romantic relationships among young Chinese adults, a research field few scholars have evinced interest in at this point in time (Lim \& Soriano, 2016: p. 4). The overarching question "What is the 'Chinese-ness' of the mobile phone user culture of young romantic couples regarding perpetual contact, boundary maintenance, and the connectedness-autonomy tension?" was answered by $15 \mathrm{semi}$-structured individual interviews. The findings suggest that 1 ) WeChat messaging was the most prominent mobile media platform used by the respondents to stay in "perpetual contact", i.e., defined as a continuous conversation through frequent short messages between individuals not physically in the same location (Katz \& Aakhus, 2002: p. 2). The interviewees wished to protect their relationship a couple by not disclosing too much or by preventing others from prying too far into it. 3) Respondents resolved the tension between the needs to connect with each other and to remain independent individuals by adopting the former approach. Respondents frequently practiced perpetual contact, supporting the Apparatgeist theory, which views mobile phones as mystical devices that allow constant communication with unseen others, combined with the collective construction of meaning (Katz \& Aakhus, 2002). This current study further discusses relevant theoretical and social implications.
\end{abstract}

\section{Keywords}

Qualitative Study, Mobile Communications, Romantic Relationship, Apparatgeist Theory, China 


\section{Introduction}

The current study aims to obtain a better picture of the "Chinese-ness" of mobile phone use by young couples to gain a deeper understanding of a crucial factor that is shaping contemporary Chinese society: romance.

This study analyzed empirical evidence that follows three dominant themes of the theoretical framework. The framework consists of the Apparatgeist theory and its underlying logic of connected presence/perpetual contact. The former sees mobile phones as mystical devices allowing constant communication with unseen others, combined with the collective construction of meaning (Katz \& Aakhus, 2002; Katz, 2007: p. 389). The latter is defined as continuous conversation through frequent short messages (Licoppe, 2004: p. 135). The second concept adopted for the theoretical framework is boundary maintenance, a problem that has emerged among couples because cell phones can blur the line between the public and private spheres (Peng \& Chu, 2012: pp. 391-392). The third concept for the theoretical framework is the connectedness-autonomy relational dialectic, i.e., the contradictory needs in a relationship to feel connected and remain an independent individual (Baxter \& Montgomery, 1996; Rawlins, 1992, as cited in Duran et al., 2011: p. 21). Hence, this study aims to answer the following overarching question:

What is the "Chinese-ness" of the mobile phone user culture of young couples regarding perpetual contact, boundary maintenance, and connectedness-autonomy tension?

The objectives of the present study are threefold:

- To describe how young Chinese couples use mobile phones

- To identify the predominant mobile media apps used and the practices employed by couples to communicate

- To discuss the theoretical and social implications of mobile communications based on empirical evidence in the Chinese context

\section{Materials and Methods}

\subsection{Rationale for the Qualitative Method Used}

The current study recruited 16 respondents by adopting the approaches of personal invitations, announcements, and snowballing, because of their easy and convenient access to potential interviewees. Semi-structured, in-depth, qualitative interviews were chosen to fit the explorative nature of the study. Respondents were interviewed individually, except for interview in which a couple was interviewed together. This study employed individual interviews, because of the intimate nature of the topic. With individual interviews, there are fewer social constraints for the romantic partner to stick to a particular narrative.

Interviews were 20 to 60 minutes in length and all were tape-recorded and fully transcribed. All of the interviews were conducted using WeChat video call, most of them in English. Before the interviews, all of the respondents were informed about the subject of discussion, the length of the interview, and how the 
interview would be used for the current study. Their consent was obtained to record and transcribe the interview. Since the focus of the analysis lies in the content rather than linguistics, the author chose a denaturalized transcription approach. Some responses were slightly edited without changing their original meanings due to the fact that all the participants in this study were non-native English speakers.

\subsection{The Participants}

The respondents were all Mainland Chinese (half males and half females) in their $20 \mathrm{~s}$ and early $30 \mathrm{~s}$ in committed heterosexual relationships. All had college degrees and lived in different parts of China, mostly Shanghai. Two of the respondents belonged to the Chinese diaspora in France. Other respondents were from Beijing, Huhehaote, Jilin province, and Fuzhou. For the most part, they were either graduate students or young professionals. Their relationships varied substantially in length (3 months to 15 years) and thus in stage (long-distance relationship [LDR], living separately, sharing an apartment, engaged, married, and/or with children). Respondents opted to use pseudonyms to ensure their anonymity (See Table 1 for more details).

\subsection{Data Collection}

The data collected included demographics and information about the quality of their romantic relationship, cell phone and app preferences and practices, and opinions about the effects of cell phone and social media use on their relationship

Table 1. Overview of the participants.

\begin{tabular}{ccccccc}
\hline Pseudonym & Sex & Place & Occupation & Age & State of relationship & Length of relationship \\
\hline Françoise & F & Paris & Graduate intern & 25 & Living together & One year \\
Claus & M & Shanghai & IT & 26 & Engaged, living together & One year \\
Katherine & F & Shanghai & Student & 24 & LDR & Two years \\
Angela & F & Shanghai & Student & 21 & LDR & Two years \\
Tobias & M & Shanghai & Graduate intern & 25 & Living separately & Four years \\
Caroline & F & Shanghai & Marketing research & 27 & LDR & Six years \\
Wendy & F & Paris & IT & 26 & Engaged, living together & Three years \\
Michelle & F & Shanghai & Sales manager & 33 & Married, living together & Nine years \\
Rebecca \& Lance & F/M & Jilin province & Official/student & $23 / 22$ & LDR & One year \\
Ted & M & Huhehaote & Freshly graduated & 25 & LDR & Three months \\
Yann & M & Shanghai & IT & 27 & LDR & Two years \\
Monica & F & Fuzhou & Student/Chinese teacher & 28 & Married, living together & 12 years \\
Lele & F & Shanghai & Student & 24 & Living separately & Two years \\
Darren & M & Shanghai & Accountant & 26 & Living together & Two years \\
Jasper & M & Beijing & Film director & 29 & Married, living together & 15 years \\
\hline
\end{tabular}


(see the interview guide in the supporting information). The semi-structured guide was used to lead the interview but did not confine the conversation.

\section{Results}

The following empirical evidence answers the overarching question concerning the "Chinese-ness" of the mobile phone user culture of young romantic couples regarding perpetual contact, boundary maintenance, and the connectedness-autonomy tension. While analyzing the information collected from the interviews, it became clear that 1) the respondents had developed the habit of being in perpetual contact with their romantic partner; 2) they were aware of the problems posed by the public/private sphere dichotomy implied by the cell phone; and 3) the informants were affected by the connectedness-autonomy dialectic inherent in mobile communication.

\subsection{Perpetual Contact}

The first theme recognized that the practice of perpetual contact dominates the mobile communications of young Chinese couples. The maintenance of perpetual contact is more important than the information shared.

\subsubsection{WeChat Is the Preferred Application for Perpetual Contact}

WeChat is the most popular messaging app for achieving a connected presence. Respondents maintain an ongoing conversation, or they keep each other updated by sending short messages when separated. Participants become accustomed to receiving messages consistently on WeChat.

Ted, whose girlfriend studies abroad, stated, "I check my phone very, very frequently. I don't want to miss any messages from her."

When asked how frequently he talks with his girlfriend, Yann answered, "Every day, every night. To keep this relationship, you know. To keep this relationship well, we need to know each other well. And I like that."

For the couples not living together, conversations over WeChat last from early morning till late at night.

Katherine said, "Yes, it's kind of like a habit. Before I go to bed, or before he goes to bed, we like, text each other." Another informant, Tobias, said that he would check on his girlfriend once an hour to make sure she was OK.

The interviewees prefer WeChat messaging over SMS or phone calls. They enjoy its convenience and practicability under different circumstances. Chatting does not need to interrupt a given situation and does not disturb anyone. Françoise said:

"Because it's more convenient. You don't need to find a place to make a phone call; you just send a message. We use WeChat all the time. It is very practical. And it s even better than a phone call. Usually, when it s not an urgent situation, we just leave a message on WeChat and wait for the reply."

Because WeChat is the number one app for communicating with their partners, the participants put their partners on their favorite lists. They use the func- 
tion "sticky on top" to fix their significant others at the top of their chat history. They choose unique wallpaper as the chat background, and they sometimes give their partners nicknames, employing such virtual means, to show affection. Caroline's boyfriend is a case in point:

"I have, you know, in my WeChat name, I have two penguins. He changed his. He added two penguins to his name," she said.

WeChat has a social media function wherein users can post photos and comments, providing another channel for couples to communicate and show affection. For some couples, liking and commenting on a loved one's posts in a timely manner is a way to express affection.

Researcher. "Do you sometimes visit her "moments" and like them or write comments below her posts?"

Interviewee: "Yes, all the time. And it has to be very fast."

Researcher. "Why? Why so fast?"

Interviewee: "Because that means (laughs), that means to her I read her posts, and am interested in them. It means I care about her, I think." (Tobias)

Instead of sending each other private messages, some of the respondents said that occasionally they would communicate via public posts. Ted pointed out that whenever his girlfriend posts something on her WeChat "moments," he has to like and comment:

"Uh, yes, I think I must do that. Because sometimes, she shows photos in her "moments," maybe she just wants me to see them and respond. Because you know that some people show things just because they want someone important to them to see them."

Françoise regards "moments" as a good way to stay abreast of what is happening in her boyfriend's daily life, and so does Caroline's boyfriend. He stated, "I think, like, for him, he checks my 'moments' sometimes because we are busy, we don't talk a lot, he can check my 'moments' to see what I'm doing, and sometimes I post three or four messages," she said.

Although Caroline asked her boyfriend if he considers her three to four daily posts excessive, her boyfriend explained that he was quite happy with the number. Sometimes she tells him something, but he already knows it from her WeChat "moments."

\subsubsection{High Expectations on Responsiveness}

For Claus, it took some time to get used to the fact that his girlfriend was busy at work and could not get back to him more than two or three times during the day. "In high school, if a girl did not answer me in 10 minutes, I would think that something was wrong. Now, I view things with a much more relaxed attitude," he said.

Being in the state of perpetual contact implies that the respondents expect a quick answer when they send a WeChat message to their partners. For some, it is a matter of minutes rather than hours.

Asked about when she would start to worry if there was no answer, Caroline 
said, "Just like maybe... up to five minutes! More makes me nervous, really. Because normally we get back to each other very quickly."

Some respondents, such as Jasper, said that they would send another message or call their partner if there was no reply. "I used to be like this: When I sent her a message, and she didn't answer after a few minutes, I would call her. If she didn't even take the call, I would worry even more about her," he said.

If the gratification of the need for a connected presence fails to be fulfilled in time, the respondents report disappointment. When perpetual contact is interrupted and the connected presence of two partners ends, the psychological consequences can be quite dramatic. Rebecca said:

"I got a little sad. Sometimes he's very busy. When I missed him, I sent him messages. But he couldn't read them, you know... Sometimes he received my messages and just ignored them."

The interviewees describe the feeling of receiving no response from their partner not only as worrisome, but also as an unfilled expectation, which makes them sad, angry, or suspicious.

"I just made a phone call to my mother. When my girlfriend called me, she couldn't get through... When I called her back, she was angry... and asked, 'What were you doing?'. I explained, 'I was talking to my mother.'” (Lance)

\subsubsection{Coping Strategies for Managing Expectations for Perpetual Contact}

To avoid unpleasant feelings, conflict, and harm to their relationships, some respondents established a rule with their partner for times when they are not able to immediately answer a message.

“We have some rules for each other. If he doesn't answer me for more than five, or six, or more minutes, he should explain why he couldn't answer me... What the circumstances were. For example, if he is going to take a shower and cannot answer me right away... he should tell me in advance." (Angela)

In Angela's case, she and her partner agreed to that rule after a severe fight, when Angela was unable to reach her boyfriend and did not know where he was and what he was doing. Another interviewee, Ted, takes it upon himself to inform his girlfriend when he expects to be away during a particular time frame. "I send her a message, such as 'I'm busy now' or 'I am with my parents,' so that she will know that I won't be able to answer her messages very frequently," he reported.

Respondents also adopted a strategy to help them cope with the problem of unexpected interruptions of their continuous contact: They know their significant other's schedule well, so they are aware of when he or she is available to communicate.

"When someone is busy, and the other wants feedback, uh, I think that, if I like, I need to write an essay or do something, if I m busy, I will tell him beforehand, to say like over the next several hours, I will be focused on my homework, and then, he will, I think he can understand. And, like, if he is going to play basketball on the weekend that we need to arrange a time to do a video call, and he 
will tell me beforehand, and then we can arrange another time, like after he has played basketball." (Katherine)

\subsubsection{Media-Rich Communication Preferred for Important Matters}

When asked about the types of content couples exchange on WeChat, participants reported that they talked about ordinary things, for example, what they are doing, they shared articles or pictures, or discussed what to eat in the evening.

"I think ... any topic ... It's real-time when I see something interesting, or I have something I want to discuss, I will talk with her immediately, so ... it doesn't matter which specific topic it is, it just depends on what I want to say, that I want to chat with her now." ( Tobias)

The respondents expressed their preference to call each other on the phone to discuss pressing issues. Whenever they have to make sure that their partner gets the information, they opt to call. Claus explained:

"We only call each other when it is urgent, and we have to make sure the other person gets the information as soon as possible, for instance, when we finish work and have to catch a train, I will inform her which train I will take so that we can take the same one."

Also, respondents prefer not to use WeChat messages to discuss serious topics. Monica said that she avoids showing anger or sending hurtful messages on WeChat, because she does not want to start a fight over the phone. Darren, too, wishes only to talk about light topics on his mobile phone:

"So if the thing takes some time to explain, and I have to know her reaction, I think we should switch to face-to-face. For example, our future plans about work, about our life, when to marry, to blah, blah, blah, or something. It's too tiring to type it in."

Media-rich interaction, such as face-to-face communication, triumphs over media-poor interaction, such as messaging. WeChat video calls are used by many couples, for instance, Angela, whose boyfriend spent a semester in Japan as an exchange student.

"I used video calls, because they' re nice. It's a great way to see each other, the image of each other, and how we behave during the video calls. [...] If I could, I would choose video calls any time."

To sum up, perpetual contact via mobile media is widely practiced by the respondents and it satisfies their relational needs.

\subsection{Boundary Maintenance}

A second identified theme is the relationship between cell phone use and tension between the public and private spheres, which requires boundary maintenance.

\subsubsection{Private Life Allowed Not Entering the Public Sphere on WeChat}

Participants are very cautious about the amount of private information they share publicly on WeChat. They categorize their WeChat friends into different social groups as a means for deciding with whom to share more private informa- 
tion in their WeChat "moments."

Researcher. "I think on WeChat you can define different groups of friends, right? Have you uploaded a picture of you and your girlfriend on WeChat?" (i.e., How do you manage your audiences?)

Darren: "Yes, sometimes. But I categorize people into groups, you know, so I can just let my friends know."

The respondents all said that they seldom share photos showing them with their partner on WeChat to protect their privacy.

"I have added a lot of my relatives and other people, and I don't want them to see my boyfriend and me, so I seldom put up pictures," Katherine reported. Michelle said that even though she is very active on social media, she does not share a lot of pictures of her husband or daughter on WeChat to protect their privacy. For Yann, pictures of him and his girlfriend are personal, so he would only show them to close friends face to face. "I have some pictures on my computer. But, yeah, if someone comes to my house, I can share the photos with him, but not show them publicly, like on WeChat or Facebook, no," he said.

Another reason that prevents the interviewees from posting pictures of them with their partner online is the fear of public judgment. Caroline said that she prefers not to show pictures of her boyfriend because of his obesity. Tobias said that his girlfriend says that his photography skills are not good enough for WeChat. Wendy is concerned that her face is too fat, and Ted thinks that he has to wait until he has a series of attractive photos that would make a decent post.

"No ... We just have one photo of us together at my graduation ceremony. That photo is not enough to show in the "moments" ... because I am looking forward to collecting more photos, maybe six or nine, you know. In WeChat, you can show nine photos together, to make it special, to show a story, not just a photo with a lot of words, which I don't think is very good."

\subsubsection{Private Life Protected from Public Sphere Interference}

When the interviewed couples spend time together, WeChat offers distractions from their interaction as a couple. But the respondents seem to value the presence of their romantic partner too much. Ted explained:

"Play games? I never play games when we are together, but I do answer messages and phone calls, yeah. I think, if we were together and I played games, she would get very angry. That's not good behavior, I think."

According to Claus, he and his girlfriend do not appreciate it if they chat a lot with other people while they are in each other's presence. They only answer incoming calls and messages. Depending on the situation, it is also acceptable to pick up the phone at times of low-intensity interaction between the two of them, for example, in the car or while on public transportation, or when one person has already finished eating.

Yann said that when he is with his girlfriend, he puts his phone in his pocket most of the time to focus on their time, and that he only uses his phone to answer messages from his friends or colleagues. Jasper said that he does not mind 
leaving his phone at home when he goes out with his wife. Monica explained, "If we are doing something together, like watching TV or having dinner, we don't like to use our cell phones. We talk to each other, and we forget we have cell phones."

\subsubsection{Too Much Interference from the Public Sphere Creates Conflict}

Roberts \& Davis (2017) proposed that "phubbing," or "using cell phone in the presence of a romantic partner," increases conflict in romantic relationships. The interviewed couples also experienced conflict over the incursion of the public sphere into their private lives. Darren recounted that he often picks up his phone when spending time with his girlfriend, which upsets her, and she often asks him to put it away. Usually, Darren said, he listens to his girlfriend, but if he does not, she feels that Darren does not care about her.

For Rebecca, jealousy also plays a role in why she gets angry when her boyfriend uses his cell phone while they are interacting.

"When we' re together, and he plays with his phone, $1 \mathrm{~m}$ wondering who he's texting. In one year, we only have 10 days together, so I think he should spend this time with me, not with other people, or his teammates, you know."

The interviewees who reported conflict over cell phone use when spending time together usually understand their partner's reaction. They also try to use their cell phones less, but it is not always easy. Françoise said that her boyfriend talked with her about her using the phone at the dinner table. She uses her cell phone less now because "we should focus on each other." Michelle wants to decrease her cell phone use when she is with her family.

" $P m$ actually very busy with work. So, sometimes during movie night, our private time, or dinnertime, I look at my mobile phone. I have another cell phone from work, and he does complain about that. [...] We started to develop a habit, it's quite common, and I see that in the restaurants as well. When the couples are seated, everyone is looking at their mobile phones."

Michelle and her husband do things very differently. She is a Porsche saleswoman, and she uses a professional and a private phone to network with her clients. Her husband, a hairdressing instructor, is "not a mobile phone person." He does not understand why she would want to post a picture of her meal, because, in his view, her WeChat friends do not ultimately care about her, so she should spend more time with him.

\subsubsection{Coping Mechanisms to Reduce Conflict Caused by "Phubbing"}

The respondents have adopted rules on when it is OK to use their phones, and when it is not, when they are together. "Sometimes he's looking at his phone, I'm looking at my phone, and then we will remind each other that it's time to stop this," Caroline said.

Claus and his girlfriend only use their cell phones when they must.

"We have a tacit agreement that we are to focus on each other when we are together. We only pick up our phones on weekends maybe six times a day. If my 
girlfriend picks up her phone, I will remind her of our agreement. I don't feel much appreciated if I am with someone who is answering messages or doing something else with their phone when I am present."

Lele uses a different strategy to prevent her boyfriend from getting too distracted by his phone. "If we are out, and he wants to watch an NBA game or something, and he wants to check the score, I may say: 'Let me check it for you.' So he won't touch his phone," she said.

When Michelle and her family are on vacation, she has to buy her husband a coffee every time she turns on her phone. Tobias said that it is strange to him to see two people having dinner, but instead of talking, they just look at their phones.

"When we are together, actually, we have a deal, because in the beginning, we had some arguments about this, so we have this deal that we won't pick up our phones when we are together unless it's something urgent, like our parents calling us, or a call from work. Otherwise, we just spend our time together, without our phones."

In short, Chinese couples have a strong tendency to care about mixing their private/public spheres and seek strategies to handle this tension to help in the development of their relationships.

\subsection{Autonomy vs Connectedness Dialectic}

The third theme of mobile communication among Chinese couples is the autonomy vs connectedness dialectic. Cell phones enable loved ones to keep in touch, but it can be quite stressful to be constantly available. Having a very deep connection with a romantic partner while maintaining autonomy is a fundamental human struggle that is only made more pronounced by cell phones.

\subsubsection{Connectedness and Dependency Preferred State of Romantic Relationship}

If the young Chinese interviewed for the current study had to choose between autonomy and connectedness, they would probably choose the latter. The sharing of one's mobile phone password with one's romantic partner exemplifies this argument. Personal privacy seems to encompass the couple as a unit, phones included. Without a single exception, all of the participants said that their partner knows their phone lock screen password or that they had saved their own fingerprint in their partner's smartphone, so they can unlock it.

Yann, for example, said, "Yes, she does know that. When she asked me that, I told her, directly, without any hesitation. There's nothing on my phone she can't see, She can see anything she wants."

The respondents often argued that they still respect their partner's privacy and do not interfere in his or her private conversations. Not checking each other's phone is not a question of privacy, but of trust in the partner's integrity. To the respondents, partners have nothing to hide from each other.

Jasper stated: "There is no privacy between us." Moreover, Angela said,

"I think that we respect each other's privacy. He said, there's nothing private 
for him, nothing private on his mobile that he can't show to me, but I haven't unlocked his phone without his permission."

The couples in this study not only share their passwords openly, but also music subscriptions, photo streams, and cloud accounts. Several respondents reported playing a mobile phone game together, such as the popular game Yin Yang Shi. It is not considered intrusion when an individual is doing something on his or her phone and their partner takes a look out of curiosity.

"And we usually share our 'moments,' so when I check my 'moments,' he comes and looks, and when he checks his, I take a look, too. And I ask, 'Who is this?' and he asks me the same question sometimes." (Françoise)

\subsubsection{Conflict Caused by Overdependence}

Young Chinese prefer connectedness over autonomy in their romantic relationships. Nevertheless, some interviewees experienced tension, such as Ted. "Sometimes, she calls me, but I am a little busy, not with something very important, but I need to decide whether to take her phone call or continue doing what I'm doing," he said.

Tobias, whose girlfriend studies abroad, feels he has to give up a little bit of autonomy for the relationship.

"That's the biggest problem between us because I need to wait until midnight to call her. So that's, uh, a bit tough. Because I am a man, I need to sacrifice more. So I need to wait until midnight to call her and then we talk around one hour before I go to sleep. The next day, I have to work. How do you say that ... I am used to it. So it's not a big deal for me."

The obligation of constant communication is not always pleasant for Yann.

"Sometimes after a whole day of work, I feel tired, so I do not want to call, because it's too late. I want to rest. So sometimes I just send her a message and say "Good night, I feel a little tired today, can we chat tomorrow?" or something. Sometimes, she understands, but most of the time, she feels angry because she thinks that I don't like her or help her. Sometimes, this drives me crazy."

The respondents in long-distance relationships seem to have an especially ambivalent relationship with mobile phones. It enables them to maintain their relationship, but it also keeps them in the "prison" of perpetual contact and from being present in the moment.

Caroline, who lives in a different city from her boyfriend, does not want to use her phone all the time but feels that she does not have a choice. "Every day, when I wake up, I need to say hello to him... It makes you feel like a machine, not like a person," she said.

Another respondent, Lance, also described the feeling of being obliged to use his mobile phone even if it makes him uncomfortable:

"Yeah, you know, how do you say it... I m a science guy. I don't want to talk too much, so.... On the other hand, I have to use the phone. Sometimes, if I leave my phone in my dormitory and I go to the library or a classroom, it feels so good. So I think smartphones just take up my time." 


\subsubsection{Conflict Caused by Too Much Autonomy}

Wendy feels that the cell phone connects her and her boyfriend. However, it also creates separate spaces of autonomy when they are together.

"The positive side is, like when I read some information, funny pictures, or stories, I can share with him immediately... On the negative side, there's less conversation, and we always focus on smartphones. Even when we re face to face, we're always playing games, and we never look into the other's face... In some ways, with the mobile phone, we' re closer, and in other ways, it creates distance."

Rebecca said that connectedness is crucial because speaking to her boyfriend, who lives $2000 \mathrm{~km}$ away, provides her with emotional support in difficult times. However, the autonomy that WeChat provides for chatting with anyone makes her worry. "Maybe he is ... he is ... no, no, no ... maybe he is active with some other girls ... so, I'm just not sure," she said.

In short, the connectedness-autonomy dichotomy represents a real struggle for the respondents of this study. However, faced with feeling tension over staying connected with their significant others and having some free space of their own, they tend to choose the former.

\section{Discussion and Conclusion}

This section discusses the findings and interpretations based on previous research and the theoretical framework of this study.

\subsection{Discussions of the Results}

First, all of the respondents stated that the presence of their partner is more important than a cell phone. These findings are consistent with Xia's (2012) suggestion that Chinese people care about their close relationships most, because social ties have a significant cultural value in a collectivist society such as China (pp. 140-141). Thus, the informants typically value the relationship with their partner more than relations with their WeChat friends. However, there is important spillover from public to private life and vice versa, as Lanigan (2009: pp. 591-592) also suggested.

Second, the cell phone provides the possibility of private communication in the public sphere and creates room for the public to enter into the private sphere; it thus increases the permeability in family boundaries (Lanigan, 2009: p. 591; Peng \& Chu, 2012: pp. 190-191). The cell phone is a kin to a door that can be opened by the user to let the two spheres merge. In contrast to the findings of Peng \& Chu (2012), which show that Chinese are seldom aware of the line between the public and the private when using their phones, it was discovered that the distinction matters very much to the Chinese couples interviewed for the current study.

Third, mobile technology can potentially bring a couple closer together and push it further apart (Hall \& Baym, 2012: p. 317). The Chinese couples interviewed prefer connectedness over autonomy. This may be a common strategy for managing relational dialectic and reducing conflict (Duran et al., 2011: p. 32; 
Hall \& Baym, 2012: p. 317). It is likely that the Apparatgeist increased expectations for perpetual contact and allowed the young couples to steer toward dependence and connectedness, as suggested by other researchers (Katz \& Aakhus, 2002, as cited in Hall \& Baym, 2012: p. 324; Duran et al., 2011: p. 21).

\subsection{Theoretical Contributions}

The respondents' cell phone use very clearly follows the logic of connected presence (Licoppe, 2004), meaning that the two individuals in a romantic relationship are in "perpetual contact" (Katz \& Aakhus, 2002) via mobile media, WeChat messaging, video calls, and "moments." Romantic relationships among young Chinese adults seem to be highly "connected" relationships. Being in a connected presence affects the expectations for a partner's responsiveness, as evinced by Miller-Ott et al. (2012: p. 31) and Hall \& Baym (2012: p. 319). Contact prevails over content among many of the interviewed Chinese couples, meaning that they often communicate to maintain a continuous conversation rather than to discuss a specific topic. This insight confirmed Katz's findings (2007) when he continued his research on the Apparatgeist theory (p. 391). Since perpetual contact was frequently practiced by the respondents as confirmed by previous research on samples from other cultures, these results overall show firm support for the Apparatgeist theory (Katz \& Aakhus, 2002). The Apparatgeist of the mobile phone seems to create a uniform and universal culture of mobile phone use among couples and may not be considerably different whether they live in the East or the West. Mobile phone culture seems to dictate people's attitudes, expectations, and behaviors toward mobile phone use in romantic relationships, at least to a certain extent.

Moreover, the findings suggest that social acceptance of mobile phones among young adults in China is particularly advanced and that the Apparatgeist has strengthened to a greater extent than in other country/region. Young Chinese share their cell phone pass codes with their partners and regard this as common and normal behavior for couples. They may perceive mobile media as an integral part of a romantic relationship for the young generation in China almost to the extent that without it, there would be no relationship. This is naturally even more valid for long-distance relationships, such as those in this study. Compared to the findings on mobile phones and romance in the United States, young Chinese couples seem to communicate more over their mobile phone. The need and expectations to stay in perpetual contact are stronger, as shown in the frequency of contact and preference for media-rich mobile communication. The young couples regulated cell phone use more and effectively managed the boundaries between their public and private spheres.

\subsection{Social (Practical) Implications}

The present study uncovers the social consequences of high cell phone penetration and the social development of mobile technologies. Couples steer, therefore, toward dependence due to higher expectations for perpetual contact mediated 
by texting and other mobile media. If the expectations for connected presence are fulfilled, it may lead to higher relational satisfaction, according to research by Hall \& Baym, 2012: pp. 324-325, or lower in the case of overdependence (idem.) Increased rulemaking for boundary maintenance in cell phone use among partners in a romantic relationship, found to be a tendency by the present research, can lead to both higher and lower relational satisfaction, depending on the specific rules, according to research by Miller-Ott et al., 2012: pp. 27-29. Current research suggests, however, that the cultural significance of what is expected and accepted still differs slightly in China and the United States. Research suggests that dependence is preferred in romantic relationships, and the need for autonomy may be less developed among young Chinese adults. Furthermore, rulemaking seems to contribute to conflict avoidance and thus higher relational satisfaction. Chinese cultural values, such as the importance of social ties, seem to affect boundary maintenance. The relationship between increased perpetual contact, dependency, and rulemaking on the one hand and relational satisfaction on the other should therefore be studied further in the Chinese context.

\subsection{Limitations and Future Research}

Although the current pilot study provides valuable insight into the young Chinese couples and the effect of the mobile phone culture on their relationships regarding perpetual contact, boundary maintenance, and the connectedness-autonomy dialectic, there are some limitations to the findings. This study claims to provide only an exploration into the mobile phone user culture of young couples in China. The small sample limits the generalization of the findings. In addition, the recruitment method led to a social selection of the study sample. For further research, a larger sample of subjects from more diverse social backgrounds might lead to different findings. A dyadic study design might produce additional valuable information that only emerges from the interaction of the two individuals in a romantic relationship.

The current study further suggests that the variables of length, stability, and type of relationship may influence cell phone use among young romantic couples in China. For example, a married woman interviewed reported less perpetual contact with her husband via the mobile phone after years of marriage and living together, but more conflict over "phubbing." On the other hand, interviewees in a long-distance relationship reported increased mobile phone communication, the expectation of perpetual contact, more conflict, and rulemaking related to the connectedness-autonomy tension. Further variables that might influence cell phone use in romantic relationships in China may be age, gender, and level of education, as found by previous research, for example, Coyne et al., 2011.

\section{Funding}

Funding source: Beijing Xijia Great Edu Tec Co., Ltd. 


\section{References}

Baxter, L. A., \& Montgomery, B. M. (1996). Dialectical Approaches to Studying Personal Relationships (pp. 1-15). New York City: Guilford Press.

Coyne, S. M., Stockdale, L., Busby, D., Iverson, B., \& Grant, D. M. (2011). “I luv u:)!”: A Descriptive Study of the Media Use of Individuals in Romantic Relationships. Family Relations, 60, 150-162. https://doi.org/10.1111/j.1741-3729.2010.00639.x

Duran, R. L., Kelly, L., \& Rotaru, T. (2011). Mobile Phones in Romantic Relationships and the Dialectic of Autonomy versus Connection. Communication Quarterly, 59, 19-36. https://doi.org/10.1080/01463373.2011.541336

Hall, J. A., \& Baym, N. K. (2012). Calling and Texting (Too Much): Mobile Maintenance Expectations, (Over) Dependence, Entrapment, and Friendship Satisfaction. New Media \& Society, 14, 316-331. https://doi.org/10.1177/1461444811415047

Katz, J. E. (2007). Mobile Media and Communication: Some Important Questions. Communication Monographs, 74, 389-394. https://doi.org/10.1080/03637750701543519

Katz, J. E., \& Aakhus, M. A. (2002). Perpetual Contact (p. 301). Cambridge: Cambridge University Press. https://doi.org/10.1017/CBO9780511489471

Lanigan, J. D. (2009). A Sociotechnological Model for Family Research and Intervention: How Information and Communication Technologies Affect Family Life. Marriage \& Family Review, 45, 587-609. https://doi.org/10.1080/01494920903224194

Licoppe, C. (2004). “Connected” Presence: The Emergence of a New Repertoire for Managing Social Relationships in a Changing Communication Technoscape. Environment and Planning D: Society and Space, 22, 135-156. https://doi.org/10.1068/d323t

Lim, S. S., \& Soriano, C. (2016). A (Digital) Giant Awakens-Invigorating Media Studies with Asian Perspectives. Asian Perspectives on Digital Culture: Emerging Phenomena, Enduring Concepts, 15, 1.

Miller-Ott, A. E., Kelly, L., \& Duran, R. L. (2012). The Effects of Cell Phone Usage Rules on Satisfaction in Romantic Relationships. Communication Quarterly, 60, 17-34. https://doi.org/10.1080/01463373.2012.642263

Peng, Y., \& Chu, R. W. C. (2012). 13 Mobile Phone Usage in Chinese Society. Mobile Communication and Greater China, 1, 189.

Rawlins, G. J. (1992). Compared to What? An Introduction to the Analysis of Algorithms. Principles of Computer Science Series. New York: Computer Science Press.

Roberts, J. A., \& David, M. E. (2017). Put Down Your Phone and Listen to Me: How Boss Phubbing Undermines the Psychological Conditions Necessary for Employee Engagement. Computers in Human Behavior, 75, 206-217. https://doi.org/10.1016/j.chb.2017.05.021

Xia, Y. (2012). Chinese Use of Mobile Texting for Social Interactions: Cultural Implications in the Use of Communication Technology. Intercultural Communication Studies, 21, 131-150. 


\section{Appendix}

\section{Interview guide}

- Introduce yourself: name, age, job/studies, level of degree/education, place, home province, etc.

- How long have you been a couple?

- Do you live together?

- Do you have plans for the future (for example, marriage, children, projects, travel)?

- What do you most use your phone for (chatting, gaming, news, videos, shopping)?

- Name all of the app/functions/media you use to communicate.

- How much do you expect your partner to contact you when you are not together? Do you expect an immediate response?

- What is the most common content of your communication with each other (expressing affection, serious/light topics, scheduling, fighting, apologizing)? Which issues do you think are better suited to discuss face-to-face, rather than by mobile phone?

- What is your partner's name in your phone's contact list? Is your partner "sticky to the top" in your WeChat or in your favorite contacts? Have you personalized your WeChat wallpaper?

- Are you and your partner in the same chat groups or mostly in separate ones? Does it make you uncomfortable when your partner (often) chats with other people?

- Do you upload to your social media profile pictures showing the two of you? When your partner uploads pictures of the two of you, what do you think/how do you feel?

- Do you look at each other's "moments" and posts? Do you like and comment on them?

- Do you take selfies together?

- What app do you use most when your partner is present (answering email, chatting, gaming, music)? Which app do you wish your partner would not use so often?

- How often do you connect with others or use your favorite apps when your partner is present? Do you also do so in bed, when the lights are out? Do you/does your partner think it is a problem?

- Do you know your partner's phone code? Do you sometimes check your partner's phone?

- Have you developed habits, rituals, practices, expressions, uses, or rules together with regard to mobile phones (for instance, turning it off at special times, the cloud, sharing apps or music lists)?

- What are some positive and negative effects does mobile phone use have on your relationship?

- Are you happy with the way you use cell phones in your relationship, or 
would you like to change a few things?

- Does cell phone use create conflict?

- Have you had conflicts over when and how much you contact each other?

- How important are smartphones in your relationship, for your relationship? Why? In what way? Provide examples. 